\section{Spontaneous carotid artery dissection}

Denis Jabaudon, $M D$, PhD, Roman Sztajzel, MD, Geneva, Switzerland

A 62-year-old man presented to the emergency department several hours after the onset of disturbed speech and right body weakness. Neurologic examination revealed motor aphasia and a right facio-brachio-crural sensorimotor hemisyndrome. A left sylvian ischemic lesion was present on CT scan. Panel A of the figure shows right facial paralysis of the central type (i.e., with sparing of forehead musculature) as well as unexpected left ptosis and myosis (partial left Horner syndrome). The latter findings raised the suspicion of a left internal carotid artery (ICA) dissection with secondary injury to the ipsilateral perivascular sympathetic plexus. On contrast-enhanced MRI (figure, B), the left ICA was no longer detectable $2 \mathrm{~cm}$ after the common carotid bifurcation (full arrow), indicating reduced blood flow in this vessel. A transverse view (figure, C; dotted line in B) confirmed that the stroke was secondary to left ICA dissection by showing torn vessel wall (open arrowhead), crescent-shaped hematoma (open arrow), and reduced lumen (full arrow). The patient was anticoagulated and partially recovered over the following months.

Address correspondence and reprint requests to Dr. Denis Jabaudon, Neurology Department, Geneva University Hospital, Switzerland.
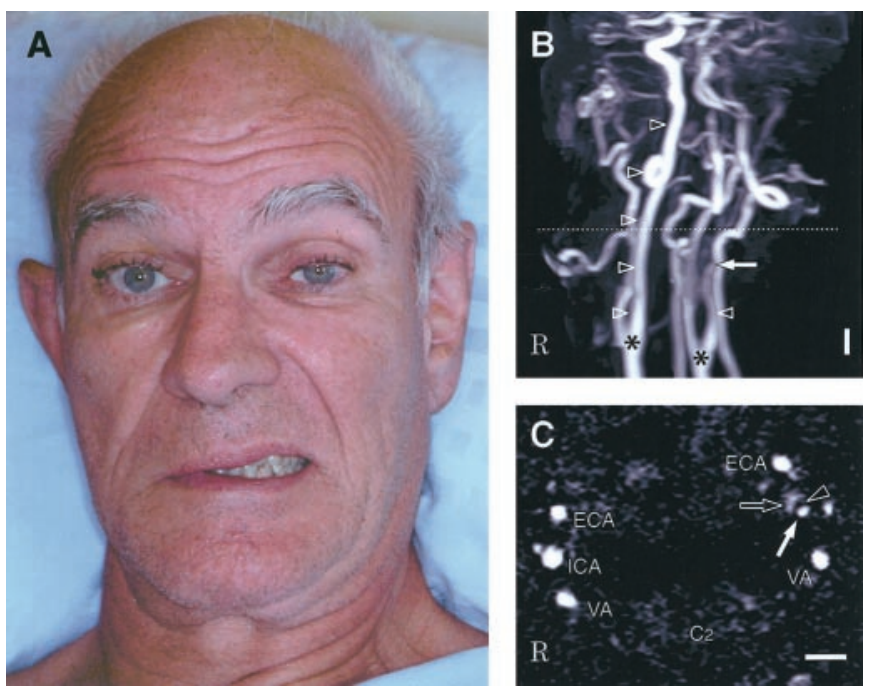

Figure. Asterisks indicate common carotid bifurcation; rightward open arrowheads, normal right internal carotid artery (ICA); leftward open arrowhead, proximal left ICA. ECA = external carotid artery; VA = vertebral artery; $\mathrm{C}_{2}=$ body of $C_{2}$. Scale bars $1 \mathrm{~cm}$. 


\title{
Neurology
}

\author{
Spontaneous carotid artery dissection \\ Denis Jabaudon and Roman Sztajzel \\ Neurology 2004;62;281 \\ DOI 10.1212/WNL.62.2.281
}

This information is current as of January 26, 2004

\section{Updated Information \&}

Services

Permissions \& Licensing

Reprints including high resolution figures, can be found at: http://n.neurology.org/content/62/2/281.full

Information about reproducing this article in parts (figures,tables) or in its entirety can be found online at:

http://www.neurology.org/about/about_the_journal\#permissions

Information about ordering reprints can be found online:

http://n.neurology.org/subscribers/advertise

Neurology ${ }^{\circledR}$ is the official journal of the American Academy of Neurology. Published continuously since 1951, it is now a weekly with 48 issues per year. Copyright . All rights reserved. Print ISSN: 0028-3878. Online ISSN: 1526-632X.

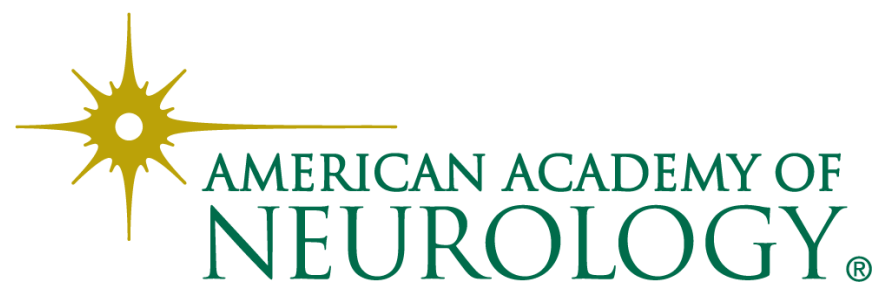

